\title{
Genochondromatosis type 2
}

INSERM

\section{Source}

INSERM. (1999). Orphanet: an online rare disease and orphan drug data base.

Genochondromatosis type 2. ORPHA:93398

Genochondromatosis type 2 is a rare genetic bone development disorder characterized by normal clavicles and symmetrical, generalized metaphyseal enchondromas,

particularly in the distal femur, proximal humerus, and bones of the wrists, hands, and feet. Lesions reg ress later in life with growth cartilage obliteration. Clinical examination is normal and the course of the disease is benign. 